\title{
The Effects of the Welding Parameters on Tensile Properties of RSW Junctions of DP1000 Sheet Steel
}

\author{
Muhammed Elitas \\ Faculty of Technology \\ Department of Manufacturing Engineering \\ Karabuk University \\ Karabuk, Turkey \\ melitas@karabuk.edu.tr
}

\author{
Bilge Demir \\ Faculty of Engineering \\ Department of Mechanical Engineering \\ Karabuk University \\ Karabuk, Turkey \\ bdemir@karabuk.edu.tr
}

\begin{abstract}
In this study, the maximum tensile shear load bearing capacity of the resistance spot welded DP1000 steel was measured and the tensile shear properties of the joints were evaluated. The effects of different welding parameters on microstructure, microhardness and tensile shear properties were investigated. Weld processes were performed by using $5 \mathrm{kA}$ and $7 \mathrm{kA}$ weld currents and 2-6bar electrode pressures. The microstructure of the welded materials was evaluated and the hardness profiles were determined. Experimental results showed that increasing electrode pressure and weld current increased the tensile shear load bearing capacity. It was also observed that the expulsion had a negative effect on the tensile shear load bearing capacity.
\end{abstract}

Keywords-DP1000 steel; welding; microhardness; tensile shear properties; expulsion

\section{INTRODUCTION}

Resistance spot welding (RSW) is one of the oldest electrical welding processes. RSW is a process used in the automotive industry especially for sheet materials, which is often preferred as the joining technique. Automobile body structure is often joined with the spot welds $[1,2]$. The advantages of spot welding are that it is relatively fast, durable and economical. However, to apply spot welds and to meet user requirements, the parts must have somewhat large dimensions. For this reason, it is expected to be replaced by a laser welding or combination of joined techniques in the future. This will allow the engine industry to build structures that are lighter and have improved rigidity and strength [1-4]. RSW is a simple manufacturing process. For automotive applications, it is accepted that the available material has a good spot weldability, and this depends on the sheet thickness, the morphology and the mechanical properties of the base metal [1, 2]. After spot weld, considerable changes occur in the mechanical and metallurgical properties of the RSW regions and heat affected zone (HAZ). It is very important to investigate these changes for the safety strength of the welded joints. The primary welding parameters (weld time, welding current, electrode pressure) affect the heat input. Primary welding parameters also affect welding quality factors like surface appearance, weld nugget size, weld penetration and weld internal discontinuities [5].
It is reported that the effect of reducing the thickness of sheet metal used in automobiles on vehicle weight is about $24 \%$. The production of these parts with new generation steels is of significant importance. Especially dual phase (DP) steels are widely preferred. The use of these steels has increased rapidly in the automotive industry due to their higher strength values per unit weight. While DP350, DP500, and DP600 steels were used initially, today the use of DP760 and DP1000 steels is becoming more widespread. The numbers after DP abbreviation express the tensile strength of the material in $\mathrm{MPa}$ and it is seen that materials with higher tensile strength and thinner section are more preferred [6]. Dual phase steel is the first generation of the advanced automotive sheet steel. Currently, it is heavily used in the automotive industry and it is estimated that it will continue to be used in the future, due to its unique economic and technologic properties. In this study, DP1000 steel was used. There are very few studies in literature related to the effect of the RSW process on the tensile shear properties of the DP1000 steel. Due to their importance in academic working and industrial area, RSW of the dual phase steel was studied in detail. It is very important to determine the optimum levels of the welding parameters to obtain a weld of desired quality [7]. In the experimental study, optimization of different welding current and electrode pressure in RSW of DP1000 steel was aimed.

\section{EXPERIMENTAL PROCEDURE}

The commercial DP1000 automotive sheet steel was $500 \times 500 \mathrm{~mm}$ and had $1.2 \mathrm{~mm}$ thickness. The microstructure of DP1000 steel mainly consists of ferrite and martensite phases. The microstructure and chemical composition of commercial DP1000 automotive sheet steel are shown in Figure 1 and Table I, respectively.

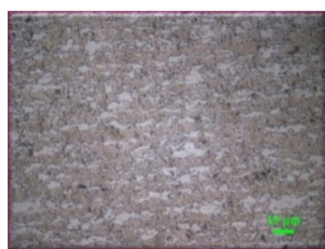

Fig. 1. Microstructure of DP1000 steel 
TABLE I. CHEMICAL COMPOSITION OF DP1000 STEEL (\%)

\begin{tabular}{|c|c|c|c|c|c|c|c|}
\hline Material & $\mathbf{C}$ & $\mathbf{S i}$ & $\mathbf{M n}$ & $\mathbf{P}$ & $\mathbf{S}$ & $\mathbf{C r}$ & $\mathbf{N i}$ \\
\hline \multirow{3}{*}{ DP1000 } & 0.136 & 0.203 & 1.57 & 0.021 & 0.003 & 0.022 & 0.039 \\
\cline { 2 - 8 } & $\mathbf{A l}$ & $\mathbf{T i}$ & $\mathbf{V}$ & $\mathbf{N b}$ & $\mathbf{C u}$ & $\mathbf{F e}$ & $\mathbf{C o}$ \\
\cline { 2 - 8 } & 0.044 & 0.001 & 0.009 & 0.021 & 0.01 & 97.897 & 0.021 \\
\hline
\end{tabular}

The specimens were prepared in accordance with EN ISO 14273 standards for RSW. The technical drawing of the specimen is shown in Figure 2.

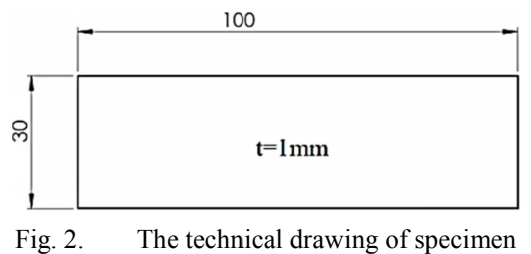

Specimens were subjected to RSW using $8 \mathrm{~mm}$ copper electrodes with flat conical tip at different welding parameters [8]. The applied currents were $5 \mathrm{kA}$ and $7 \mathrm{kA}$ and the electrode pressures were 2-6bar. RSW was applied by taking three samples for each electrode pressure. The RSW process used in this study was carried out considering some of the ideal RSW parameters used in the literature and these parameters are shown in Table II $[9,10]$. Time unit is cycle-based (1 cycle $=0.02 \mathrm{~s})$. A resistance spot welded specimen is shown in Figure 3. Transverse metallographic specimens of the DP1000 steel and specimens passing through the central part of the welded pieces were prepared by the standard method. The polished specimens were etched with a $2 \%$ nital solution $(2 \%$ nitric acid $+98 \%$ methanol). The microstructure was analyzed using a Nikon Epiphot 200 light microscope. The specimens used in the microstructure analyses were also used for hardness measurements. Microhardness testing was conducted using a QNEES type Vickers microhardness testing machine with a HV0.2 (1.961N) load and 15s holding time. Microhardness mapping using $0.2 \mathrm{~mm}$ grid spacing revealed the hardness distribution and the individual hardness values in selected regions of welded joints $[8,10]$. On each sample, measurements were made in one direction, along the radius of the nugget. Tensile shear tests were performed on resistance spot welded specimens. Resistance spot welded specimens had $1.2 \mathrm{~mm}$ thickness, $30 \mathrm{~mm}$ width and $110 \mathrm{~mm}$ gauge length. The crosshead speed used for the tensile shear test was $2 \mathrm{~mm} / \mathrm{min}$ [8].

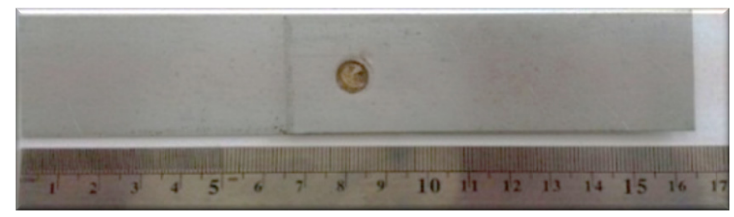

Fig. 3. Resistance spot welded specimen

\section{RESULTS AND DISCUSSION}

\section{A. Microstructure}

In this study, ten different RSW samples were obtained. These samples' structures were examined visually and by stereo and optic microscopy. Visual inspection results showed that welding samples were obtained normally. Figure 4 shows an example of weld profile as macro structure of DP1000 RSW sample welded with 7kA-2bar. Moreover, microstructure images of HAZ and weld metal of the all RSW samples are shown at Figures 5 and 6 . As seen in these Figures, microstructures of the weld metal are formed as martensites. As mentioned in the related literature, these results could be estimated for general grade of dual phase steels because of the higher alloying content of the commercial dual phase steels and therefore higher hardenability.

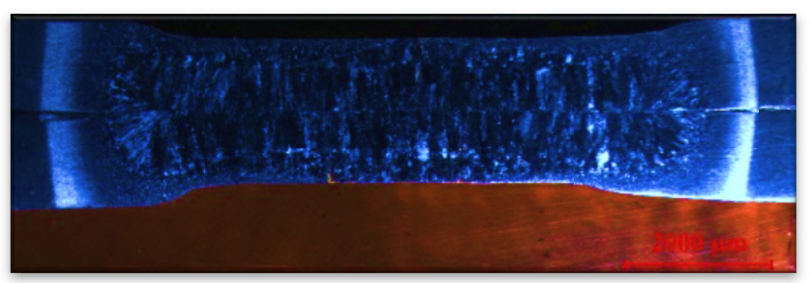

Fig. 4. Macro structure of DP1000 RSW sample welded with 7kA-2bar

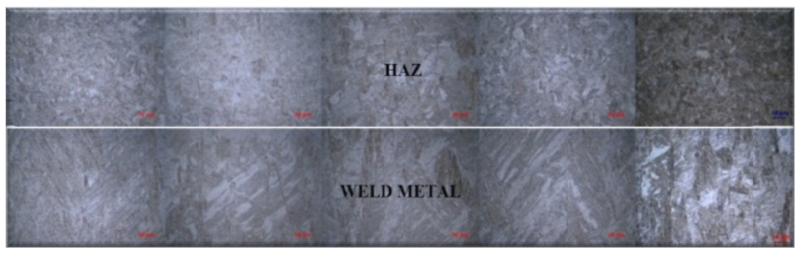

(a)

(b)

(c)

(d)

(e)

Fig. 5. HAZ and weld metal microstructures at different electrode pressures and 5kA welding current a) 2bar, b) 3bar, c) 4bar, d) 5 bar, e) 6 bar

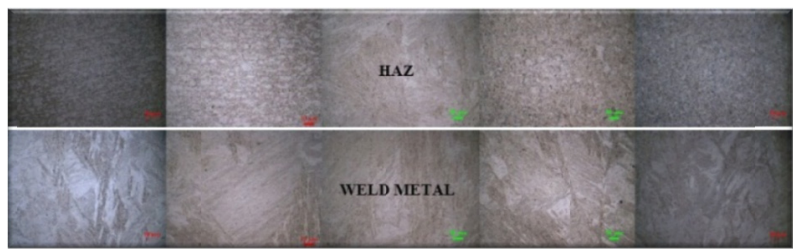

(a)

(b)

(c)

(d)

(e)

Fig. 6. HAZ and weld metal microstructures at different electrode pressures and $7 \mathrm{kA}$ welding current a) 2bar, b) 3bar, c) 4bar, d) 5bar, e) 6 bar

Contrast to the related literature, it could be said that the HAZs of the RSW samples are showing nearly wholly martensite although little lowering throughout transition zone. It was observed that, dual phase microstructures consisted of ferrite and martensite phases for all electrode pressures [11, 12]. Indeed, the main difference between DP600 and DP1000 microstructures is the martensite volume fractions (MVF). DP1000 comprises higher MVF than DP600 to ensure higher strength as $1000 \mathrm{MPa}$ because the strength of dual phase steel rises essentially with the hard martensite phase. Cooling rate in the weld metal is quite high because sheet metal specimens' thinness and the water-cooled electrodes. Therefore, there is not enough time for carbon diffusion. As a result, microstructure in the weld metal and HAZ predominantly 
consists of martensite phase $[1,11]$. Generally, MVF increased throughout the base metal, HAZ and weld metal for all electrode pressures. This is explained as "the rate of ferrite dissolved in the austenite from base metal towards the weld metal increases because of rapid cooling after welding process and therefore this may increase the MVF" [10].

TABLE II. WELDING PARAMETERS FOR RSW PROCESSING

\begin{tabular}{|c|c|}
\hline Electrode pressure(bar) & $2-6$ \\
\hline Welding current (kA) & $5-7$ \\
\hline Electrode tip diameter(mm) & 8 \\
\hline Down time (cycle) & 15 \\
\hline Squeeze time (cycle) & 35 \\
\hline Welding time (cycle) & 20 \\
\hline Hold time (cycle) & 10 \\
\hline Separation time (cycle) & 15 \\
\hline
\end{tabular}

\section{B. Microhardness}

Microhardness results obtained in the RSW processes are shown in Figures 7 and 8. It can be seen that the hardness of the weld metal in DP steels increases considerably after the RSW process. The hardness can become about 2 times that of the base metal. As hardness increases, strength also increases. However, as hardness increases, embrittlement and toughness may decrease. Therefore, it is important to analyze and understand the hardness and metallurgical structure of DP steels [13, 14]. Martensitic transformation is a hardening and strengthening mechanism for steels. It is well known that martensite is strong phase due to its microstructure which consists of high carbon content and high unmobile dislocation density. This is due to the volume expansion during austenite transformation to martensite. Hard and strong martensite is a good resistance barrier against dislocation slip actions and movements in dual phase structure. DP steels contain martensite and ferrite phases at the beginning of the RSW. Martensite and ferrite volume fractions are $70 \%$ and $30 \%$ respectively in DP1000 steel. During welding processes, the very fast heating and cooling cycle leads austenite to martensite transformation. In welding, weld metal cools from austenite phase, even some HAZ also cools from austenite and thus these zones have higher hardness than the base metal [15]. It could be evaluated that hardness values of the specimens are in usable range for all welding parameters. To explain hardness, dependence on martensite is a good way $[9,10,12,15]$. Authors in [11] reported that, increasing of heat input increases the generation of higher amount of martensite deformation induction which causes higher hardness [11]. In other words, dual phase steels essentially contain two phases. During spot welding, melting and then solidification occurs at the current flowing and squeezing stages. Throughout weld cooling solidification, austenitization and then transformation or austenite decomposition occur. Here, cooling rates are quite fast. Because of these fast cooling rates and higher amount alloy elements' content, weld metal has higher hardenability for DP1000, higher compared to DP600. There is a very interesting result about HAZs from DP600. HAZ of the RSW samples showed higher hardness than DP600. These results also may be able to explain what was discussed above about the effects of the hardenability and cooling rates on properties.
As seen in Figures 7 and 8, higher martensite means higher hardness. Several researchers have given some useful relationships between martensite mass carbon content and material's hardness. Author in [16] reported that, martensite hardness, in case of exceeding $0.05 \%$ of mass of carbon content, is expected to be more than $350 \mathrm{HV}$. In this study, carbon content of the used steel sheet materials confirmed this rule. All weld metal specimens' hardness of different welding parameters have shown hardness values higher than $350 \mathrm{HV}$ as seen in Figures 7 and 8 which show the differences between $7 \mathrm{kA}$ and $5 \mathrm{kA}$ samples hardness results.

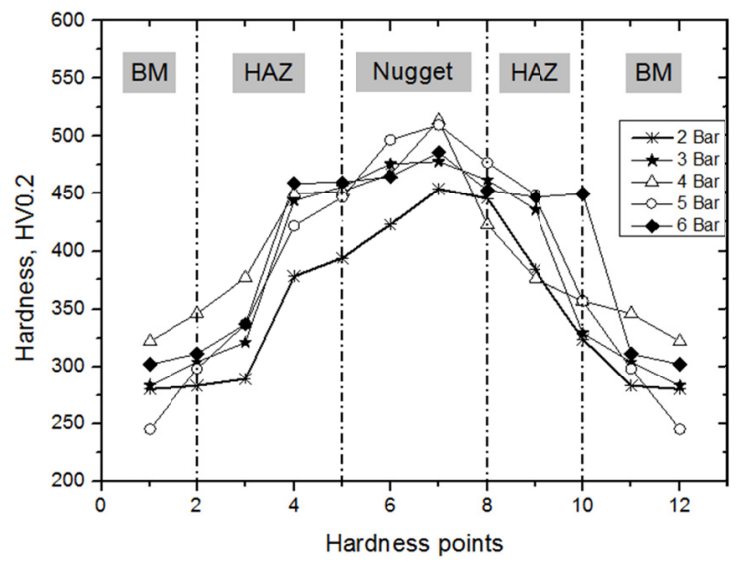

Fig. 7. Hardness values of the $5 \mathrm{kA}$ weld current samples with different weld pressures

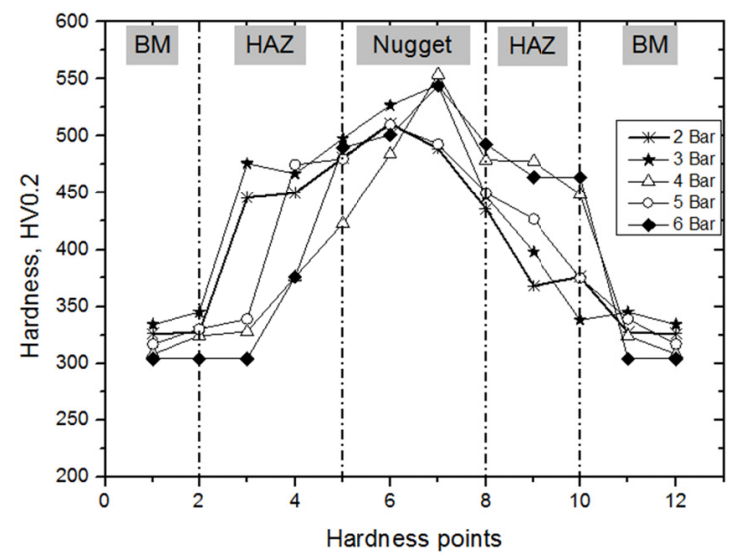

Fig. 8. Hardness values of the $7 \mathrm{kA}$ weld current samples with different weld pressures

\section{Tensile Properties}

In this study, the maximum tensile shear load bearing capacity of the specimens during the tensile shear test was measured and the strength properties of the joints were evaluated [10]. The effects of different welding parameters on tensile shear properties were investigated. Tensile shear tests were performed to the joined samples to determine their tensile shear load bearing capacity which is one of the parameters having effect on the joint quality. Tensile shear forces of all the samples are given in Figure 9. As can be seen, the highest tensile-shear load bearing capacity pertains to the sample of the 
joined at 3bar electrode pressure, $7 \mathrm{kA}$ welding current. Conversely, the lowest tensile shear load bearing capacities are seen for the sample joined at $4 \mathrm{bar}$ electrode pressure, $5 \mathrm{kA}$ welding current.

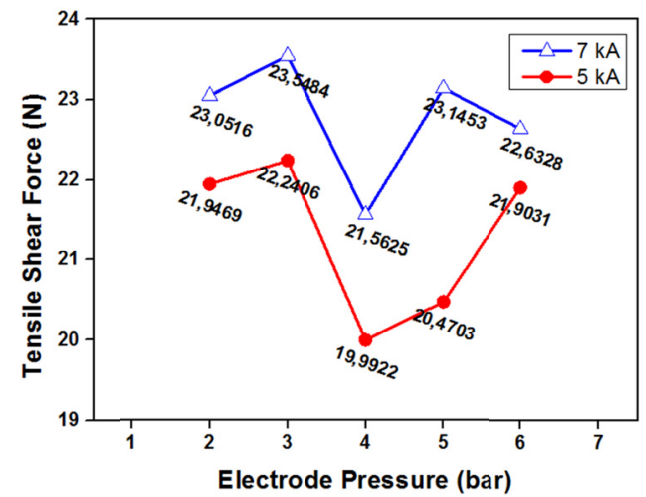

Fig. 9. Maximum tensile shear force values obtained at different welding parameters

When the effects of electrode pressures were evaluated, it has been observed that increasing electrode pressure increases the tensile shear load bearing capacity of the joints. An explanation can be that heat input in the welding zone in resistance spot welding which is calculated by the use of the $\mathrm{Q}=\mathrm{I}^{2} \mathrm{Rt}$ equation where $\mathrm{I}=$ current passing through the sample, $\mathrm{R}=$ total resistance and $\mathrm{t}=$ welding time. With increasing electrode pressure, total resistance $\mathrm{R}$ decreases when the current increases. This increase in the weld current increases the heat input of the sample during current passing time of the welding. This, in turn, increases the tensile shear load bearing capacity of welded joints [17]. Author in [18] indicated that electrode pressure in RSW has affected the joint's strength. It is observed from Figure 9 that increasing welding current increases heat input. Authors in [19-22] investigated RSW and they all stated that increasing welding current increased tensile shear load bearing capacity of the samples.

Expulsion formation during the welding process is often determined by many complicated parameters, such as thermal, electrical, metallurgical, and mechanical processes [23, 24]. It always occurs at the faying surface of the upper and lower steel sheets or the electrode/workpiece interfaces. Expulsion occurring at the faying surfaces is often a result from excessive welding time, welding current or insufficient electrode pressure. As the total useful welding heat implemented to the weld metal exceeds a critical value, the molten metal cracks the liquid nugget and expulsion happens [25]. Failure energy delineates the weld energy absorption capability and fracture toughness against loads. As can be seen in Figure 9, the failure energies of the welds with expulsion $(5 \mathrm{kA}-4 \mathrm{bar}, 7 \mathrm{kA}-4 \mathrm{bar}$, $7 \mathrm{kA}-6$ bar) are smaller than the ones of the welds without expulsion. Compared to welds without expulsion, the tensile shear load bearing capacity of the welds with expulsion is a little smaller. Consequently, quality control of the resistance spot welded joints is usually determined by tensile shear tests. When the tensile shear curves in Figure 9 are analyzed, it is seen that increasing electrode pressure and weld current increases the tensile shear load bearing capacity. It can be said that this in turn increases the toughness of the joints.

\section{CONCLUSIONS}

In this study, the maximum tensile shear load bearing capacity of the specimens during tensile shear tests was measured and the strength properties of the joints were evaluated. The effects of different welding parameters on microstructure, microhardness and tensile shear properties were investigated. The conclusions resulting from this study are:

1. It could be said that microstructures of the weld metal were formed as martensite and HAZs of the RSW samples were showing nearly wholly martensite.

2. Generally, martensite volume fractions increased for all welding parameters.

3. The hardness of the weld metal in DP steels considerably increases after the RSW process. Hardness can increase about 2 times compared to the base metal. It was observed that, HAZ and weld metal had higher hardness than base metal.

4. All RSW samples, which had been welded by using different parameters, showed hardness values higher than $350 \mathrm{HV}$. These were explained with carbon content rules in this study.

5. It was observed that, the highest and the lowest tensileshear load bearing capacities pertain to the samples of the joined at $7 \mathrm{kA}-3$ bar and $5 \mathrm{kA}-4$ bar respectively.

6. It is seen that increasing electrode pressure, and weld current increased the tensile shear load bearing capacity.

7. Compared to welds without expulsion, the tensile shear load bearing capacity of the welds with expulsion (5kA4bar, 7kA-4bar, 7kA-6bar) was a little smaller.

\section{ACKNOWLEDGMENT}

This work was supported by the Scientific Research Projects Coordination Unit of Karabuk University (Karabuk, Turkey). Project Number: KBUBAP-17-KP-463.

\section{REFERENCES}

[1] M. Elitas, B. Demir, O. Yazici, "The effects of the electrode pressure on tensile strength and fracture modes of the RSW junctions of DP600 sheet steel", 2nd International Conference on Material Science and Technology in Cappadocia, Nevsehir, Turkey, October 11-13, 2017

[2] B. Demir, "An investigation on the production of dual-phase steel from AISI 4140 and its impact strength at different martensite volume fractions", Metallofizika I Noveishie Tekhnologii, Vol. 29, No. 9, pp. 1159-1166, 2007

[3] Y. Cho, S. Rhee, "Experimental study of nugget formation in resistance spot welding", Welding Journal, Vol. 82, No. 8, pp. 195-201, 2003

[4] C. A. Campos, M. P. Guerrero-Mata, R. Colas, R. Garza, "Weldability of galvannealed interstitial free steel”, ISIJ International, Vol. 42, No. 8, pp. 876-881, 2002

[5] F. Hayat, B. Demir, M. Acarer, S. Aslanlar, "Effect of welding time and current on the mechanical properties of resistance spot welded IF (DIN EN 10130-1999) steel”, Metallic Materials, Vol. 47, No. 1, pp. 11-17, 2009

[6] B. Aydemir, E. Aydemir, E. Kaluc, "Investigation of tensile and fatigue properties of DP1000 steel sheets joints with remote laser (RLW) and resistance spot welded (RSW)", Engineer and Machinery, Vol. 58, No. 687, pp. 17-28, 2017 
[7] A. W. El-Morsy, M. Ghanem, H. Bahaitham, "Effect of friction stir welding parameters on the microstructure and mechanical properties of AA2024-T4 Aluminum alloy", Engineering, Technology \& Applied Science Research, Vol. 8, No. 1, pp. 2493-2498, 2018

[8] F. Hayat, I. Sevim, "The effect of welding parameters on fracture toughness of resistance spot-welded galvanized DP600 automotive steel sheets", The International Journal of Advanced Manufacturing Technology, Vol. 58, No. 9-12, pp. 1043-1050, 2012

[9] C. Ma, D. L. Chen, S. D. Bhole, G. Boudreau, A. Lee, E. Biro, "Microstructure and fracture characteristics of spot-welded DP600 steel", Materials Science and Engineering A, Vol. 485, No. 1-2, pp. 334346, 2008

[10] M. I. Khan, M. L. Kuntz, E. Biro, Y. Zhou, "Microstructure and mechanical properties of resistance spot welded advanced high strength steels", Materials Transactions, Vol. 49, No. 7, pp. 1629-1637, 2008

[11] T. K. Pal, K. Bhowmick, "Resistance spot welding characteristics and high cycle fatigue behavior of DP780 steel sheet", Journal of Materials Engineering and Performance, Vol. 21, No. 2, pp. 280-285, 2012

[12] O. Holovenko, M. G. Ienco, E. Pastore, M. R. Pinasco, P. Matteis, G. Scavino, D. Firrao, "Microstructural and mechanical characterization of welded joints on innovative high-strength steels", La Metallurgia Italiana, Vol. 3, pp. 3-12, 2013

[13] F. Hayat, B. Demir, M. Acarer, "Tensile shear stress and microstructure of low-carbon dual-phase $\mathrm{Mn}-\mathrm{Ni}$ steels after spot resistance welding", Metal Science and Heat Treatment, Vol. 49, No. 9-10, pp. 484-489, 2007

[14] B. Demir, M. Erdogan, "The hardenability of austenite with different alloy content and dispersion in dual-phase steels", Journal of Materials Processing Technology, Vol. 208, No. 1-3, pp. 75-84, 2008

[15] H. Karakus, B. Demir, M. Elitas, "The effects of the electrode type on microstructure and hardness of the RSW of DP600 steel", 2nd International Conference on Material Science and Technology in Cappadocia, Nevsehir, Turkey, October 11-13, 2017

[16] W. D. Callister, Fundamentals of materials science and engineering, John Wiley and Sons, 2004

[17] Y. Kaya, N. Kahraman, "The effects of electrode force, welding current and welding time on the resistance spot weldability of pure titanium", The International Journal of Advanced Manufacturing Technology, Vol. 60, No. 1-4, pp. 127-134, 2012

[18] L. M. Gourd, Principles of welding technology, British Library Cataloguing in Publication Data, 1995

[19] M. Vural, A. Akkus, "On the resistance spot weldability of galvanized interstitial free steel sheets with austenitic stainless steel sheets", Journal of Materials Processing Technology, Vol. 153-154, pp. 1-6, 2004

[20] P. Marashi, M. Pouranvari, S. Amirabdollahian, A. Abedi, M. Goodarzi, "Microstructure and failure behavior of dissimilar resistance spot welds between low carbon galvanized and austenitic stainless steels", Materials Science and Engineering: A, Vol. 480, No. 1-2, pp. 175-180, 2008

[21] S. Fukumoto, K. Fujiwara, S. Toji, A. Yamamoto, "Small-scale resistance spot welding of austenitic stainless steels", Materials Science and Engineering: A, Vol. 492, No. 1-2, pp. 243-249, 2008

[22] D. Q. Sun, B. Lang, D. X. Sun, J. B. Li, "Microstructures and mechanical properties of resistance spot welded magnesium alloy joints", Materials Science and Engineering: A, Vol. 460-461, pp. 494498, 2007

[23] M. R. Arghavani, M. Movahedi, A. H. Kokabi, "Role of zinc layer in resistance spot welding of aluminium to steel”, Materials \& Design, Vol. 102, pp. 106-114, 2016

[24] A. Ramazani, K. Mukherjee, A. Abdurakhmanov, M. Abbasi, U. Prahl, "Characterization of microstructure and mechanical properties of resistance spot welded DP600 steel”, Metals, Vol. 5, No. 3, pp. 17041716,2015

[25] D. Zhao, Y. Wang, D. Liang, P. Zhang, “An investigation into weld defects of spot-welded dual-phase steel", The International Journal of Advanced Manufacturing Technology, Vol. 92, No. 5-8, pp. 3043-3050, 2017 